\title{
SHAPING ABILITY OF DIFFERENT SINGLE NiTi FILES: A CBCT ASSESSMENT
}

\author{
Bahar JaAfar Selivany and ANas Hussein Yousif \\ Dept. of Conservative Dentistry, College of Dentistry, University of Duhok, Kurdistan Region-Iraq
}

(Received: July 7, 2020; Accepted for Publication: August 28, 2020)

\begin{abstract}
Aim : The study aimed to compare Shaping ability of WaveOne Gold, Reciproc Blue and 2Shape NiTi systems having different design and metallurgic properties.

Method : Forty five extracted human single root with $10 \mathrm{~mm}$ root length were randomly divided into three groups (Group one- Wave One Gold, Group two-Reciproc Blue, Group three- 2Shape rotary ) .CBCT images were taken before and after the instrumentation for each group, centering ability ,canal transportation and removal dentin thickness were evaluated for each group. Data were statistically analyzed using one way ANOVA and Ductan test.

Result : The results of canal centering ratio ,canal transportation and dentin thickness removal showed that no significant difference was found among the three file groups at the $1 \mathrm{~mm}, 3 \mathrm{~mm}$ and $5 \mathrm{~mm}$ levels $(p<$ 0.05).

Conclusion: It can be concluded that WaveOne Gold, Reciproc Blue and 2Shape preserved the original canal anatomy well.
\end{abstract}

KEYWORDS: Centering ability. Canal transportation. Removal dentin thickness. WaveOne Gold . Reciproc Blue $\cdot 2$ Shape .

\section{INTRODUCTION}

$\mathbf{T}$ The primary aim of endodontic treatment is to promote the shaping followed by cleaning of the root canal, to attribute a conical shape and to preserve the originally existing root canal curvature. Nevertheless, throughout chemo-mechanical preparation, deviations from the original root canal curvature may occur (Singh et al.,2019a)

Respecting the original canal anatomy during shaping procedures of narrow curved root canals, is an important and a demanding step for clinicians (Schäfer and Lohmann,2002).

There are no instruments available which are capable of identically shaping the root canal walls ( Foschi et al.,2004) ; however, nickeltitanium (NiTi) rotary instruments produce less transportation and more centralized preparations when compared to stainless steel instruments (Singh et al.,2019a) .

NiTi instruments have advantages including maintain the original shape of root canal and reducing the instrumentation error such as zipping, ledge formation, and perforation risk (Paqué et al.,2009).
Single-file shaping concepts based either on continuous rotation or reciprocation, have been introduced to simplify the instrumentation process, as well as reducing the risk of crosscontamination (De-Deus etal.,2010)

WaveOne Gold (Dentsply Maillefer), is one of the reciprocating single-file systems. The gold process is a post-manufacturing procedure in which the ground NiTi files are heat-treated and slowly cooled. It is available in four sizes as follows: small (20.07), primary (25.07), medium (35.06), and large (45.05). WaveOne Gold has a parallelogram cross-section with two cutting edges, alternate one, and two-point contact (Saritha et al., 2017).

Reciproc blue (VDW GmbH, Munich, Germany), a thermally treated NiTi file, is an improved version of the original Reciproc file. It has greater flexibility and more resistance to cyclic fatigue, The Reciproc blue instruments have an S-shaped cross-section (Yared, 2017).

2Shape (Micro Mega, Besancon, France) is a sequence consists of two shaping files in a continuous rotation That have been heat-treated using the $\mathrm{T} \cdot$ Wire technology. 2Shape has a triple helix cross-section with 2 main cutting edges (Uslu et al., 2018). 
The present study aimed to evaluate and compare the shaping ability of WaveOne Gold, Reciproc Blue, and 2Shape root canal files.

\section{METHOD}

A total of about 300 human extracted teeth with at least one curvature root were collected, The teeth had been extracted for periodontal ,caries or orthodontic reasons, then immersed in $5.25 \%$ sodium hypochlorite solution for one hour for disinfection (Gawdat and El Nasr,2018), the teeth were then rinsed under running water to eliminate sodium hypochlorite. Debris and tissue residues were removed using a ultrasonic scaler and a sterile gauze, and the teeth were stored in normal saline until the experiment, the root was separated from crown using cutting low-speed diamond disc at $10 \mathrm{~mm}$ level for standardization, for every five samples a new disc had been used.

The root were checked for canal patency by using root canal instrument size 10/0.2 ISO Kfile, and apical diameter was checked by using root canal instrument size 15/0.2 ISO K-File that fitted at the apex. Only roots with intact apices, with single canal and whose canal width near the apex was approximately compatible with size no.15/ 0.2 ISO K-file were selected (Attia et al.,2019).

Teeth with internal (pathological), external (pathological) root resorption. calcified canals, root canal treated before, incomplete root formation and roots with less than $25^{\circ}$ and more than $30^{\circ}$ curvature were excluded from this study.

The selected roots were placed in a radiographic mount made of silicon based impression material to maintain a stable position, each three roots were placed with their long axis parallel to each other and to the surface of the digital radiographic sensor as possible (Bürklein,2011).

The $\mathrm{x}$-ray tube was aligned perpendicular the roots with distance of $20 \mathrm{~cm}$. The standardized radiographs were taken in bucco-lingual direction. After the radiograph transferred to special software computer program and the degree of curvatures of the roots were obtained according to schinderian method (Schneider, 1971) .

Only roots with angles of curvatures ranging from $\left(25^{\circ}-30^{\circ}\right)$ were selected (Singh et al,2019b). A total of 45 roots among all roots were selected and then 45 roots were divided randomly into three groups each group 15 roots according to the type of single file system used for root canal preparation. The working length was obtained by measuring the length of the initial instrument no.10/0.2 ISO K-file which was just seen by naked eye at the apical foramen minus $0.5 \mathrm{~mm}$ (Vorster et al.,2018).

The roots specimens were embedded in dental plaster using a plastic mold to facilitate instrumentation process and maintained reproducibility of the Cone Beam Computed Tomography (CBCT) examination before starting canals preparation .In order to prevent the plaster from entering and setting into the apical foramen, the apices of the roots were sealed with wax. The total amount of irrigant solution was standardized for each groups by using $6 \mathrm{ml}$ of $5 \%$ sodium hypochlorite. The needle was inserted as deep as possible into the root canal without binding. The lubricating agent Glyde (Dentsply Maillefer) was put inside the canal each time before rotary instrumentation. The rotary instruments were used to enlarge three canals only and were replaced by new instruments. reproducible glide path (RGP) was ensured with size \#15/ 0.2 ISO $\mathrm{K}$ - file which was smoothly inserted and removed from the canal The flutes of the instruments were cleaned with ethyl alcohol and dried after each use, (Bürklein et al., 2011).

WaveOne Gold group (Dentsply Maillefer; Ballaigues, Switzerland) Tip size 25Taper of 0.07 used according to the manufacturer instructions; the file was introduced into the canal with in-and-out picking motion until reaching the full working length (WL). ReciprocBlue group (VDW, Munich, Germany) tip size 25 with a taper of 0.08 used in the same manner as WaveOne gold files; these two files were used in a reciprocating motion. 2Shape group (Micro-Mega, Besançon, France) tip size 25 with a taper of 0.06 used according to the manufacturer instructions using a speed of 350 $\mathrm{rpm}$ and maximum torque of $2.5 \mathrm{Ncm}$.

All canals were instrumented with X-smart IQ endodontic motor (Dentsply Maillefer, Switzerland)

After instrumentation, $1 \mathrm{~mL}$ of $17 \%$ ethylenediaminetetra acetic acid (EDTA) was applied for $2 \mathrm{~min}$ followed by final irrigation with $3 \mathrm{~mL}$ of $\mathrm{NaOCl}$ (Singh et al,2019b). After finishing the steps of instrumentation and irrigation size $25 \mathrm{k}$-file was inserted to the full 
working length to check that instrumentation was completed. Then size \#25 of paper point was used for drying the canal.

\section{Evaluation of shaping ability by Cone Beam Computed Tomographic (CBCT):}

All teeth in each group were scanned before and after mechanical preparation with Cone Beam Computed Tomography (CBCT) (NewTom Giano Verona, Italy). Sections were taken at 1,3 and $5 \mathrm{~mm}$ levels from apex.

The distance from the internal canal wall to the external root surface was measured at the mesial and distal on preoperative and postoperative images of each level (Fig.1).

The canal centering ability throughout shaping and cleaning was concluded through measurement the shortest distance from the outer surface of instrumented and uninstrumented canal to the periphery of the root (mesial and distal) and compare these measurements. The formula that used for the calculation of root canal centering ability was: :(a1-a2) $\div($ b1-b2) or $(b 1-b 2) \div(\mathrm{a} 1-$ a2). Which is,

a1: is the shortest distance from the mesial edge of the root to the mesial edge of the uninstrumented canal.

b1: is the shortest distance from distal edge of the root to the distal edge of the uninstrumented canal.

a2: is the shortest distance from the mesial edge of the root to the mesial edge of the instrumented canal.

b2: is the shortest distance from distal edge of the root to the distal edge of the instrumented canal (Shivashankar et al., 2016)(Fig.2).

A outcome equal to 1.0 reveal complete centralization. When this value was closer to zero, it inferred that the instrument had a decreased capacity to preserve itself in the central line of the canal.

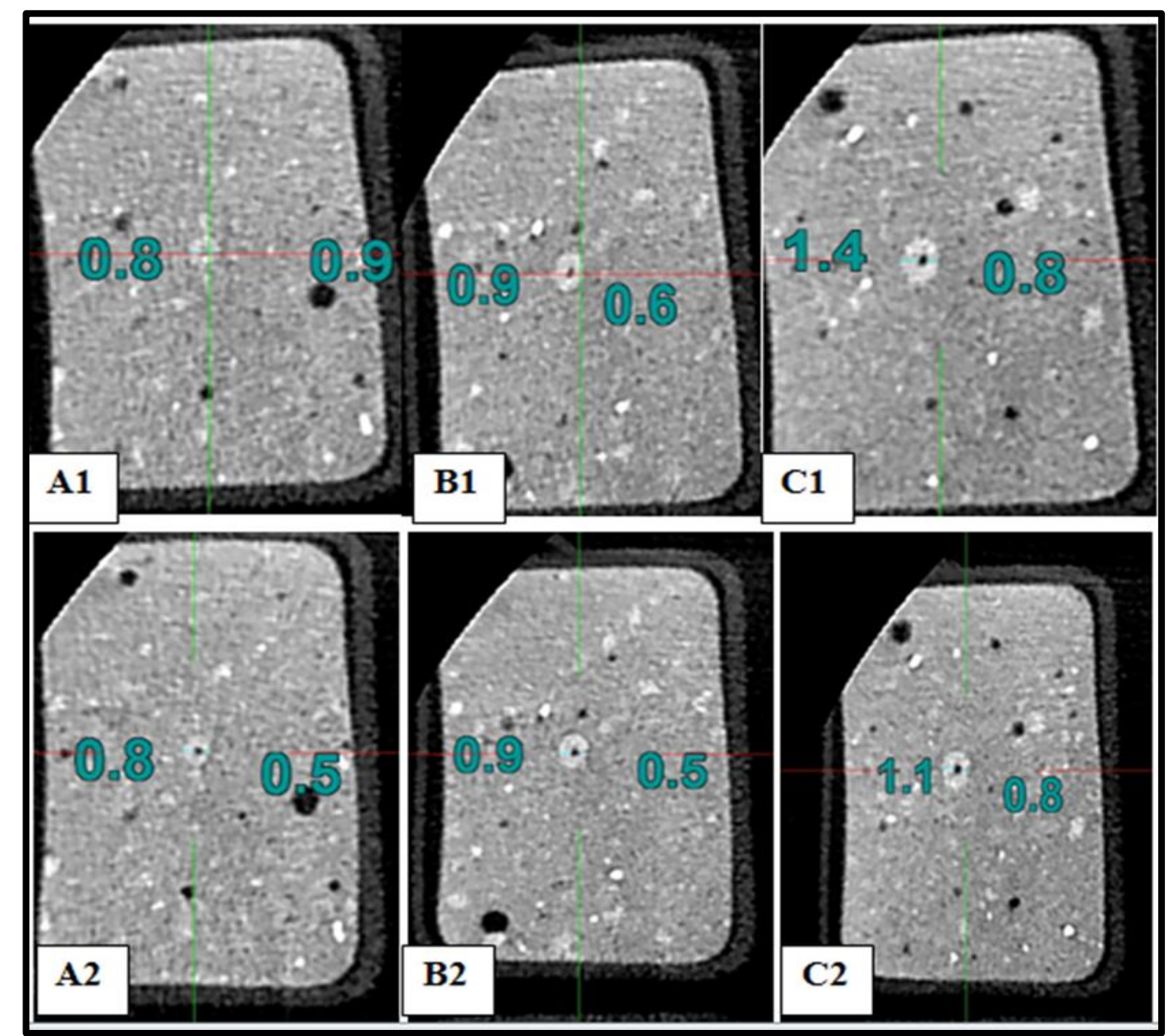

Fig.(1):CBCT measurment (A1, B1\& C1 .1, 3\& $5 \mathrm{~mm}$ levels respectively) before instrumentation and (A2, B2\& $\mathrm{C} 2.1,3 \& 5 \mathrm{~mm}$ levels respectively)after instrumentation. 
For canal transportation was: (a1-a2) - (b1b2) (Gawdat and El Nasr, 2018).

- 0 No canal transportation is evident.

- Value other than 0 indicates transportation has occurred in the canal.

- Negative value indicates transportation towards distal.
- Positive value indicates transportation towards mesial

If transportation equal to 0 (zero) indicate absence of transportation, a negative value described transportation to the distal direction, and a positive value represented transportation toward the mesial direction.

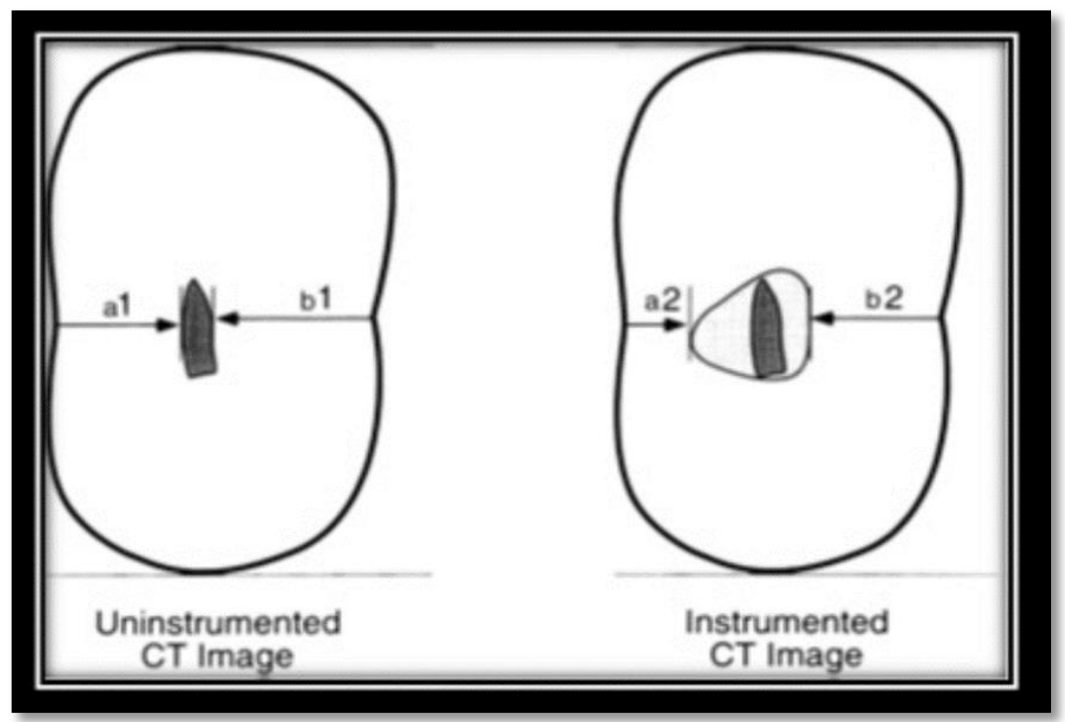

Fig. (2): Image cross sections for measurements (Shivashankar et al., 2016).

The removed dentin thickness was measured for each root canal by subtracting the uninstrumented canal volume from the instrumented canal volume (Singh et al,2019b).

\section{Statistical analysis}

Mean and standard deviations of the data obtained were analyzed using the Statistical Package for Social Sciences version 25 (SPSS 25; IMB Corp, USA). One- way ANOVA was used to determine if there were significant differences among the means of groups. Duncan method under significance level 0.05 and confidence interval of $95 \%$ was performed to find any significant differences between groups.

\section{RESULT}

Table 1,2 and 3 showed Mean, standard deviation (SD) and intergroup comparison of centering ability $(\mathrm{mm})$,canal transportation and dentin thickness removed in the level $1 \mathrm{~mm}, 3 \mathrm{~mm}$ and $5 \mathrm{~mm}$ of the canals. There was no significant difference in the measures of centering ability at the 1,3 and $5 \mathrm{~mm}$ level of the canal among WaveOne Gold, Reciproc and 2Shape files at $(\mathrm{P}<0.05)$

Table (1): Mean, standard deviation (SD) and intergroup comparison of centering ability in the 1, 3, and $5 \mathrm{~mm}$ level of the canals by ANOVA and Duncan test.

\begin{tabular}{ccccc}
\hline Level(mm) & $\begin{array}{c}\text { Waveone Gold } \\
\text { Mean } \pm \text { SD }\end{array}$ & $\begin{array}{c}\text { Reciproc Blue } \\
\text { Mean } \pm \text { SD }\end{array}$ & $\begin{array}{c}\text { 2Shape } \\
\text { Mean } \pm \text { SD }\end{array}$ & 0.343 \\
\hline 1 & $0.6667 \pm 1.17514$ & $0.4333 \pm 0.77613$ & $0.3333 \pm 0.64550$ & 0.892 \\
\hline 3 & $0.4000 \pm 0.60356$ & $0.4000 \pm 0.76064$ & $0.3667 \pm 0.48058$ & 0.662 \\
\hline 5 & $0.8667 \pm 1.17210$ & $0.8533 \pm 1.11539$ & $0.6733 \pm 1.09575$ & P-Value
\end{tabular}

A p-value $<0.05$ was considered as statistically significant level. 
Table (2): Mean, standard deviation (SD) and intergroup comparison of canal transportation in the 1, 3 , and $5 \mathrm{~mm}$ level of the canals by ANOVA and Duncan test.

\begin{tabular}{ccccc}
\hline Level $(\mathbf{m m})$ & $\begin{array}{c}\text { Waveone Gold } \\
\text { Mean } \pm \text { SD }\end{array}$ & $\begin{array}{c}\text { Reciproc Blue } \\
\text { Mean } \pm \text { SD }\end{array}$ & $\begin{array}{c}\text { 2Shape } \\
\text { Mean } \pm \text { SD }\end{array}$ & 0.503 \\
\hline 1 & $0.0067 \pm 0.20166$ & $0.0133 \pm 0.11872$ & $-0.0333- \pm 0.19881$ & 0.321 \\
\hline 3 & $-0.0133 \pm 0.24162$ & $0.0667 \pm 0.23805$ & $0.0333 \pm 0.10465$ & 0.428 \\
\hline 5 & $0.0333 \pm 0.16330$ & $-0.0133 \pm 0.1726$ & $-0.02 \pm 0.17809$ & P-Value \\
\hline
\end{tabular}

A p-value $<0.05$ was considered as statistically significant level.

Table (3): Mean, standard deviation (SD) and intergroup comparison of removal dentin thickness in the 1,3 , and $5 \mathrm{~mm}$ level of the canals by ANOVA and Duncan test.

\begin{tabular}{ccccc}
\hline Level(mm) & $\begin{array}{c}\text { Waveone Gold } \\
\text { Mean } \pm \text { SD }\end{array}$ & $\begin{array}{c}\text { Reciproc Blue } \\
\text { Mean } \pm \text { SD }\end{array}$ & $\begin{array}{c}\text { 2Shape } \\
\text { Mean } \pm \text { SD }\end{array}$ \\
\hline 1 & $0.2133 \pm 0.1641$ & $0.1733 \pm 0.1486$ & $0.2133 \pm 0.1302$ & 0.492 \\
\hline 3 & $0.280 \pm 0.22104$ & $0.3000 \pm 0.1732$ & $0.2533 \pm 0.2065$ & 0.555 \\
\hline 5 & $0.2533 \pm 0.1505$ & $0.2400 \pm 0.1502$ & $0.2333 \pm 0.1676$ & 0.744 \\
\hline
\end{tabular}

A p-value $<0.05$ was considered as statistically significant level.

\section{DISCUSSION}

One of the critical criteria and prerequisites for optimal instrumentation of the root canals is the preservation of the original canal outline, curvature, and centering. The ability of the root canal files to respect the anatomy of the canals is vital to prevent the procedural errors that may occur in different parts of the canals, such as transportation in the apical third, strip perforations in the middle third or weakening of the coronal part by cutting more cervical dentin ( Young et al.,2007).

The various thermos-mechanic procedures and the improvement of comp-osition of the alloy that is used in manufacturing NiTi files are aimed to improve the flexibility of NiTi files (Lopes et al.,2013). Improved flexibility of NiTi files would minimize the intra-canal irregularities such as canal transp-ortation and would ensure an increase in the success of root canal therapy (Özyürek et al.,2017)

In the present study cone beam computed tomography (CBCT) 'imaging technique was used for assessment of centering ability, apical transportation and removal dentin thickness, as it provides a specific, reproducible, and three dimensional assessment of dentine thickness and root canal volume alteration before and after preparation without damaging the specimens (Hartmann et al., 2007).

The angle of curvature at $25^{\circ}-30^{\circ}$ was preferred as it is considered as moderate curvature according to American Association of Endodontists (Singh et al., 2019b).

Natural teeth and simulated resin canals are used to compare the shaping abilityies of NiTi files. The methodology here employed was reproducible, precise and reliable. Moreover, the model used in this study with extracted natural teeth which allows real test conditions. Simulated artificial canals are different in terms of micro-hardness when compared to root dentin, and the effects created by heat generation during instrumentation can affect the instruments' cutting blades (Silva et a.,2016)

However, in studies using natural teeth, it is very difficult to maintain standardization because of the anatomic variations of the teeth (Peters et al 2001) .

All of the selected instruments (WG primary, RB 25 and TS 25) possess a tip diameter 
equivalent to a size 25 aiming to standardize the apical preparation size. Keeping in consideration that these files are designated for narrow and curved canals in accordance with the manufacturers recommendations. Preceding canal instrumentation, no glide path was established. However, all of the canals allowed passive placement of \# $15 \mathrm{~K}$-file to full working length as recommended by the manufacturer when preparing a curved root canal.

Prior to the use of the tested instruments, a glide path equivalent to ISO size 15 was created. Glide path preparation in canals with curvature angles between $25^{\circ}$ and $35^{\circ}$ (the same range of curvature as in the present study) even to ISO size 20 using manual stainless steel K-files had no effect on canal straightening or apical transportation (D'Amario et al,2013), and did not produce any canal aberrations (Alves et $a l, 2012)$.

Reciprocating movement minimizes torsional and flexural stresses, increases the centering ability of canal, and reduces the taper lock of the instrument within the canal (Guillén et al.,2018;Özyürek et al., 2017; Takeshi et al.,2016; Webber et al.,2016) .Saber et al (2015) showed that Reciproc and WaveOne instruments caused significantly less transportation than One Shape, which may be attributed to the use of MWire alloy in fabrication of Reciproc and WaveOne files and their reciprocating motion. Kanagasingam et al. (2016) found that reciprocating file had the best centering ability of the root canal compared to continuous rotary system. However, Cimilli and Kartal, (2005) indicated that continuous rotational motion has higher centering ability compared with reciprocating motion. Moreover, Beurklein et al., (2014)_indicated that One Shape had higher canal centering ability than Reciproc. In the study no significant difference found between reciprocating and continuous rotation.

No significant difference was noted among mean of WaveOne Gold, Reciproc Blue and 2Shape systems $(\mathrm{P}>0.05)$ in centering ability, canal transportation and removal dentin thickness ,the probable reason could be the tip design, metallurgy, file cross-section, and principle working motion of each file system. Bürklein et al (2019) state that the differences on instruments NiTi alloy, design, cross section and conicity do not affect the centralization capacity or canal transport on the curved canals preparation .The result agrees with previous study Bürklein et al.(2019) ,Silva et al.(2018) ,Singh et al.(2019a), Singh et al.(2019b). The results of present study disagrees with the results obtained by Keskin $e t$ al.(2018) that reported the superiority of WaveOne Gold over Reciproc Blue in canal centering and transportation.

WOG works on the principle of reciprocating motion and is claimed to be able to completely shape and clean root canals with only one single use instrument. These files are made of a special NiTi alloy called Gold Wire which is created by an innovative thermal treatment process. The benefits of this G-gold Wire NiTi are increased flexibility of the instruments and improved resistance to cyclic fatigue (Özyürek et al., 2017). And the parallelogram-shaped cross section with the two cutting edges limits the engagements between the file and dentine (Ruddle, 2016).

Reciproc Blue is another file used in reciprocating motion, the files are produced with Nickel-Titanium that goes through an innovative heat treatment, modifying its returnsmolecular structure to give the files an enhanced characteristics (Yared ,2017), the cross-section of Reciproc Blue files is an S-shaped with regressive taper (De-Deus et al.,2017).

2Shape (2S) NiTi rotary file works on rotating motion and is made of NiTi-alloy called $\mathrm{T}$-wire which is a method which allows for an increased resistance to cyclic fatigue $(+40 \%)$ and a better negotiation of curvatures. It return to their original shape after each use. A latest generation of cross-section with tripe helix: two primary cutting edges and 1 secondary cuttingedge aids in the perfect compromise between cutting efficiency and debris removal(Micro Mega,2017).

No statistically significant difference among three groups in level $1 \mathrm{~mm}, 3 \mathrm{~mm}$ and $5 \mathrm{~mm}$ table 1. This result showed that the motion pattern might not affect canal transportation of single file systems when the other influencing factors are identical (Naseri et al., 2016), increased flexibility of the alloys related to less canal transportation (Gagliardi et al.,2015), and this may be explained by using size 25 file and the amount of canal transportation increase with canal preparation greater than size 25 (Vallabhaneni et al., 2017).

No significant difference was noticed in mean centering ability, canal transportation and removal dentin thickness of WaveOne Gold file 
at $1 \mathrm{~mm}, 3 \mathrm{~mm}$,and $5 \mathrm{~mm}$ levels of the canal, this may be explained by the reciprocating motion that consists of a clockwise and a counterclockwise motion, and allows the file to be continuously free against the internal wall of the curvature. Also, this file was made of gold Wire alloy which increases its flexibility (Saberi et al., 2018). With notable more centering ability in level $5 \mathrm{~mm}$ than level $1 \mathrm{~mm}$ and $3 \mathrm{~mm}$ this may explain by progressive decreasing in tapering from D4-D16 .

No significant difference was noticed in mean centering ability, canal transportation and removal dentin thickness of Reciproc Blue file at $1 \mathrm{~mm}, 3 \mathrm{~mm}$, and $5 \mathrm{~mm}$ levels of the canal, with more centering in level $5 \mathrm{~mm}$ and this can be attributed to the regressive taper $\mathrm{RB}$ possess, starting at $3 \mathrm{~mm}$ from the tip till it reaches a diameter of $1.05 \mathrm{~mm}$ at D16.

No significant difference was noticed in mean centering ability, canal transportation and removal dentin thickness of 2Shape at $1 \mathrm{~mm}, 3 \mathrm{~mm}$, and $5 \mathrm{~mm}$ levels of the canal may be related to flexibility and constant taper of the file.

\section{CONCLUSION}

Within the limitations of this study, it was concluded that WaveOne Gold, Reciproc Blue and 2Shape could preserve original canal anatomy with less aggressive dentin cutting and minimal canal transportation .

\section{REFFERENCE}

Alves Vde O, Bueno CE, Cunha RS, Pinheiro SL, Fontana CE \& de Martin AS (2012). Comparison among manual instruments and PathFile and Mtwo rotary instruments to create a glide path in the root canal preparation of curved canals. J Endod; 38(1):117 - 120.

Attia DA, Alhadainy HA, Darrag AM, Ghoneim WM (2019).. Shaping ability of different root canal preparation systems. Tanta Dent J;16:17682Bürklein S, Hinschitza K, Dammaschke T \& Schäfer E (2011). Shaping ability and cleaning effectiveness of two single-file systems in severely curved root canals of extracted teeth: Reciproc and WaveOne versus Mtwo and ProTaper. Int Endod J; 45(5): 449461.
Bürklein S, Poschmann T \& Schäfer E (2014). Shaping ability of different nickel-titanium systems in simulated S-shaped canals with and without glide path .J Endod;40(8):1231-1234.

Bürklein S, Flüch S \& Schäfer E (2019). Shaping ability of reciprocating single-file systems in severely curved canals: WaveOne and Reciproc versus WaveOne Gold and Reciproc blue.Odontology ;107(1):96-102.

Cimilli H \& Kartal N.(2005). Shaping ability of rotary nickel-titanium systems and nickel-titanium kfiles in separable resin blocks .G Ital Endod;19:159-161.

D’Amario M, Baldi M, Petricca R, De Angelis F, El Abed R \& D'Arcangelo C (2013). Evaluation of a new nickel-titanium system to create the glide path in root canal preparation of curved canals. J Endod;39 (12):1581-1584.

De-Deus G, Moreira EJ, Lopes HP, Elias CN. Extended cyclic fatigue life of F2 ProTaper instruments used in reciprocating movement. Int Endod J 2010;43:1063-1068

De-Deus G, Silva EJNL, Vieira VTL, Belladonna FG, Elias CN, Plotino G, et al (2017).Blue thermomechanical treatment optimizes fatigue resistance and flexibility of the reciproc files. $\mathrm{J}$ Endod;43(3):462-466.

Delgoshayi N, Abbasi M, Bakhtiar H, Sakhdari S, Ghannad S \& Ellini MR (2018). Canal transportation and centering ability of ProTaper and SafeSider in preparation of curved root canals: A CBCT Evaluation. Iran Endod J; 13(2): 240-245.

Fallatah HY \& El Sherief SM (2018). Cone-beam computed tomography analysis of centering ability and transportation of curved root canals prepared with three rotary nickel-titanium systems (In Vitro-Study). IJS Short Rep; 3(1): 58-64.

Foschi F, Nucci C, Montebugnoli L, Marchionni S, Breschi L, Malagnino VA \& Prati C (2004). SEM evaluation of canal wall dentine following use of Mtwo and ProTaper NiTi rotary instruments. Int Endod J.;37(12):832-9.

Gagliardi J, Versiani MA, de Sousa-Neto MD, Plazas-Garzon A \& Basrani B (2015). Evaluation of the Shaping Characteristics of ProTaper Gold, ProTaper NEXT, and 
ProTaper Universal in Curved Canals. J Endod;41(10):1718-1724.

Gawdat SI \& El Nasr HMA (2018). Shaping ability and surface topography of WaveOne Gold and OneShape single files. Endod Pract Today; 12(2): 109-118.

Guillén RE, Nabeshima CK, Caballero-Flores H, Cayón MR, Mercadé M, Cai S, et al (2018). Evaluation of the WaveOne Gold and One Shape New Generation in Reducing Enterococcus faecalis from Root Canal.Dent J; 29(3):249-253.

Hartmann MS, Barletta FB, Camargo Fontanella VR \& Vanni JR.(2007). Canal transportation after root canal instrumentation: a comparative study with with computed tomography. J Endod;33(8):962-965.

Jellil EI (2017). Evaluation of canal transportation using single file rotary systems, One Shape, Waveone GOLD and Reciproc in simulated curved canals (in vitro study). Tikrit J Dent Sci; 5(1): 121-125.

Kanagasingam S, Asem B, Zainuddin NA, Nordin R and Patel S (2016). Micro computed tomography evaluation of canal preparation with protaper, waveone and reciproc rotary file systems. Int J Dent Med; 1(2): 55-59.

Keskin C , Demiral M \& Sarıyılmaz E (2018). Comparison of the shaping ability of novel thermally treated reciprocating instruments. C, Demiral M, Sarıyılmaz E Restor Dent Endod.; 43(2):e15.

Lopes HP, Elias CN, Vieira MV, Siqueira JF Jr, Mangelli M, Lopes WS, et al (2013). Fatigue life of Reciproc and Mtwo instruments subjected to static and dynamic tests. J Endod;39(5):693-696.

Micro Mega 2Shape Brochure (2017). http://micromega.com / wp content/uploads/11/Brochure_2Shape_EN1.pd f

Naseri M, Paymanpour P, Kangarloo A, Haddadpur S, Dianat O \& Ketabi MA (2016). Influence of motion pattern on apical transportation and centering ability of WaveOne single-file technique in curved root canals. Dent Res J; 13(1): 13-17.

Navós BV, Hoppe CB, Mestieri LB, Böttcher DE, Só MVR \& Grecca FS (2016). Centering and transportation: in vitro evaluation of continuous and reciprocating systems in curved root canals. J Conserv Dent; 19(5): 478-481.

Özyürek T , Gündoğar M , Koray Y \& Uslu G (2017). Bending resistance and cyclic fatigue life of Reciproc Blue, WaveOne Gold, and Genius files in a double (S-shaped) curved canal. J Dent Res Dent Clin Dent Prospects ; 11(4): 241-246.

Paqué F, Ganahl D \& Peters OA (2009). Effects of root canal preparation on apical geometry assessed by micro-computed tomography. J Endod. 2009;35(7): 1056-1059 .

Peters OA, Sch“onenberger K \& Laib A (2001). Effects of four $\mathrm{Ni}-\mathrm{Ti}$ preparation techniques on root canal geometry assessed by micro computed tomography. Int Endod J;34(3):221230.

Ruddle CJ (2016) .Single-File Shaping Technique Achieving A Gold Medal Result. Dent Today ;35(1):98-103.

Saber S, Nagy M \& Schäfer E (2015). Comparative evaluation of the shaping ability of WaveOne, Reciproc and OneShape single-file systems in severely curved root canals of extracted teeth. Int Endod J;48(1):109-114.

Saberi E, Farhad-Mollashahi N, Bijari S \& Daryaeian M (2018). Comparative evaluation of root canal transportation by three NiTi Single-File systems in curved canals: A Cone Beam Computed Tomography study. Int J Dent; : 16.

Saritha V, Kainath F, Twino H \& Kumar (2017).Cone-beam computed tomography assessment of root canal transportation using WaveOne Gold and Neoniti single-file systems.J Conserv Dent; 20(6): 434-438.

Schäfer E \& Lohmann D (2002). Efficiency of rotary nickel-titanium FlexMaster instruments compared with stainless steel hand $\mathrm{K}$ Flexofile-part 1. Shaping ability in simulated curved canals. Int Endod J;35(6):505-513.

Schneider SW(1971). A comparison of canal preparations in straight and curved root canals. Oral Surg Oral Med Oral Pathol. 1971;32(2):271-275.

Shivashankar MB, Niranjan NT, Jayasheel A and Kenchanagoudra MG (2016). Computed 
tomography evaluation of canal transportation and volumetric changes in root canal dentin of curved canals using Mtwo, ProTaper and ProTaper Next rotary system-an in-vitro study. J Clin Diagn Res; 10(11):10-14.

Silva EJ, Villarino LS, Vieira VT, Accorsi-Mendonça $\mathrm{T}$, Antunes HD, De-Deus G, et al (2016). Bending Resistance and cyclic fatigue life of Reciproc, Unicone, and WaveOne reciprocating Instruments. J Endod;42(12):1789-1783.

Silva P.F, Silva,E. Coelho,N.C.C \& Alves,S.A (2018).Canal transportation and centering ability of reciproc blue, waveone gold and protaper next in simulated curved canals . Iran Endod J ;13(4):498-502.

Singh S, Mirdha N, Shilpa PH, Tiwari RVC, Abdul MSM \& Sainudeen S (2019a).Shaping Ability of 2Shape and WaveOne Gold Files Using ConeBeam Computed Tomography. J Int Soc Prev Community Dent; 9(3):245-249.

Singh S, Abdul MSM, Sharma U, Sainudeen S, Jain C \& Kalliath JT( 2019 b). An in vitro Comparative Evaluation of Volume of Removed Dentin, Canal Transportation, and Centering Ratio of 2Shape, WaveOne Gold, and ProTaper Gold Files Using Cone-Beam Computed Tomography .Int Soc Prev Community Dent; 9(5): 481-485.
Takeshi U, Michiko H, Kaori S, Ryoichiro W, Ikuya S, Noriko M \& Nobuyuki T (2016). The study of shaping ability using WaveOne Gold. Japn J Conserv Dent;59(1):111-118.

Uslu $\mathrm{G}$, Özyürek $\mathrm{T}$, Gündoğar $\mathrm{M} \quad$ \& Y1lmaz K (2018). Cyclic fatigue resistance of 2Shape, Twisted File and EndoSequence Xpress nickel-titanium rotary files at intracanal temperatureJ Dent Res Dent Clin Dent Prospects. 2018 Autumn; 12(4): 283287.

Vallabhaneni S, Fatima K \& Kumar TH (2017). Cone-beam computed tomography assessment of root canal transportation using WaveOne Gold and Neoniti single-file systems. J Conserv Dent; 20(6): 434-438.

Vorster M, van der Vyver PJ, Paleker F(2018). Canal Transportation and Centering Ability of WaveOne Gold in Combination with and without Different Glide Path Techniques. $J$ Endod:;44(9):1430-1435.

Webber J (2016). Shaping canals with confidence: WaveOne GOLD single-file reciprocating system. Int Dent Afr Ed;6(3):6-17.

Yared G (2017). Reciproc sblue: the new generation of reciprocation. G Ital Endod; 31( 2): 96-101.

Young GR, Parashos P \& Messer HH (2007). The principles of techniques for cleaning root canals. Aust Dent J; 52(1):52-60. 